\title{
Workshop Pengajuan Sertifikat Halal bagi Pelaku Industri Makanan Olahan UMKM
}

\author{
Siska Siska1*, Hanifah Rahmi ${ }^{1}$, Fitriani $^{1}$, Ema Dewanti ${ }^{1}$ \\ Fakultas Farmasi dan Sains, Universitas Muhammadiyah Prof. Dr. Hamka, Jakarta, Indonesia \\ Email: siskaaiko@gmail.com
}

\begin{abstract}
Abstrak
Indonesia adalah negara yang memiliki warga negara mayoritas adalah umat muslim. Sebagai umat Islam, kita diwajibkan mengkonsumsi makanan/minuman yang halal. Seiring dengan hal tersebut Pemerintah telah mengeluarkan Undang-Undang Nomor 33 Tahun 2014 tentang Jaminan Produk Halal, maka semua pelaku industri baik di bidang makanan/minuman olahan, produk farmasi dan lain-lain wajib memiliki sertifikat halal. Namun hingga saat ini belum banyak indutri olahan yang mengajukan sertifikat halal terutama pada industri UMKM (usaha mikro, kecil dan menengah). Fakultas Farmasi dan sains (FFS) UHAMKA yang telah memiliki Pusat Kajian Halal UHAMKA (PKHU), berkewajiban untuk mensosialisasi dan mengedukasi kepada seluruh masyarakat mengenai pentingnya "halal" suatu produk. Target pada kegiatan workshop ini adalah pelaku usaha di bidang pengolahan makanan/minuman UMKM di wilayah Duren Sawit Jakarta Timur. Metode yang digunakan adalah dengan melakukan pelatihan/workshop tentang tatacara pengajuan sertifikat halal dan dokumen-dokumen yang harus dipersiapkan. Workshop diawali dengan sosialisasi pentingnya sertifikat halal kemudian dilanjutkan dengan pretest. Pre-test untuk melihat sejauh mana pemahaman terkait sertifikasi halal. Workshop diakhiri dengan post-test, untuk melihat peningkatan pemahaman setelah diberikan sosislaisasi dan pelatihan terkait sertifikasi halal. Hasil yang didapat adanya peningkatan pemahaman peserta $(\mathrm{p}<0,05)$ dibandingkan antara sebelum dengan sesudah pelatihan. Kesimpulan dari kegiatan ini adalah workshop yang diberikan bermanfaat untuk para pelaku usaha UMKM dalam meningkatkan pemahaman terkait tatacara sertifikasi halal.
\end{abstract}

Kata kunci: Sertifikasi halal, PKHU, pelatihan sertifikasi halal

\begin{abstract}
Indonesia is a country that has a majority of Muslims. Muslims are required to consume halal food. Along with this, the government has issued law no. 33/2014 concerning halal product assurance, then all the processed food/beverages, pharmaceutical products, and other industries must have a halal certificate. Unfortunately, not many processed industries have applied for the halal certificates, especially in the UMKM industry. The Faculty of Pharmacy and Science (FFS) of UHAMKA have already had a UHAMKA Halal Study Centre (PKHU). It is obliged to socialize and educate the whole community about the importance of the "halal" of products. The target in this workshop is UMKM food/beverage processing in the Duren Sawit area of East Jakarta. The method used is to conduct training/workshop on procedures for filing halal certificates and documents that must be prepared. The workshop began with the socialization of the importance of halal certificates and then continued with a pre-test. The pre-test aimed to see the understanding of halal certification. The workshop ended with a post-test to review an increase in knowledge after being given socialization and training of halal certification. The results obtained an increase in understanding of participants ( $p<0.05)$ compared between before and after training. This activity concludes that the workshop provided is beneficial for UMKM entrepreneurs in improving knowledge of halal certification procedures.
\end{abstract}

Keywords: Halal certification, PKHU, workshop of halal certification

Format Sitasi: Siska, Rahmi, H., Fitriani, Dewanti, E. (2020). Workshop dan Pelatihan Pengajuan Sertifikat Halal bagi Pelaku Industri Makanan Olahan UMKM. Jurnal SOLMA. Vol. 09(1):201-208. Doi: http://dx.doi.org/10.29405/solma.v9i1.3823

\begin{tabular}{l|l|l}
\hline Diterima: 03 November 2019 & | Revisi: 16 April 2020
\end{tabular}


(C) 2020 Oleh authors. Lisensi Jurnal Solma, LPPM-Uhamka, Jakarta. Artikel ini bersifat open access yang didistribusikan di bawah syarat dan ketentuan Creative Commons Attribution (CC BY) license. (http://creativecommons.org/licenses/by/4.0/).

\section{PENDAHULUAN}

Indonesia adalah negara yang memiliki warga negara mayoritas adalah umat muslim. Sebagai umat Islam, kita diwajibkan mengkonsumsi makanan/minuman yang halal. Sebagaimana disebutkan dalam Q.S. Al Baqaroh: 168 "Hai sekalian manusia, makanlah yang halal lagi baik dari apa yang terdapat di bumi, dan janganlah kamu mengikuti langkah-langkah syaitan; karena sesungguhnya syaitan itu adalah musuh yang nyata bagimu"

Indonesia sebagai negara berkewajiban untuk memenuhi kebutuhan makanan yang halal bagi warga negara yang beragama Islam. Seiring dengan hal tersebut Pemerintah telah mengeluarkan Undang-Undang Nomor 33 Tahun 2014 tentang Jaminan Produk Halal Presiden Republik Indonesia, (2014). Dengan undang-undang ini maka semua pelaku industri baik di bidang makanan/minuman olahan, produk farmasi dan lain-lain wajib memiliki sertifikat halal Setyaningsih, D, Apriyantono, A, dan Sari, (2010). Seharusnya undang - undang ini menjadi pemicu tumbuhnya industri yang halal. Tetapi kenyataannya, hingga saat ini belum banyak indutri olahan yang mengajukan sertifikat halal terutama pada industri UMKM (Usaha Mikro Kecil dan Menengah).

Fakultas Farmasi dan Sains (FFS) UHAMKA adalah salah satu fakultas di UHAMKA yang telah memiliki Pusat Kajian Halal UHAMKA (PKHU). Salah satu misi PKHU adalah mengadakan pengabdian kepada masyarakat di bidang kehalalan produk. PKHU berkewajiban untuk mensosialisasi dan mengedukasi kepada seluruh masyarakat mengenai pentingnya "kehalalan" suatu produk. PKHU wajib mendorong masyarakat untuk lebih kritis terhadap kehalalan suatu produk.

Target pada kegiatan workshop ini adalah pelaku usaha di bidang pengolahan makanan/minuman UMKM (Usaha Mikro, Kecil dan Menengah) di wilayah Duren Sawit Jakarta Timur. Pelaku usaha UMKM di bidang pengolahan makanan/minuman antara lain adalah pemilik kantin dan warung makan di sekitar FFS UHAMKA. Tujuan kegiatan ini adalah untuk memberikan pemahaman terkait tatacara sertifikasi halal. Keikutsertaan pelaku usaha ini diharapkan dapat menjaga dan menjamin kehalalan produk (makanan/minuman) yang diolahnya sehingga konsumen menjadi lebih yakin dan tenang akan makanan yang dikonsumsinya sesuai dengan syariat Islam. 


\section{MASALAH}

Banyak para pelaku usaha di bidang pengolahan makanan dan minuman UMKM seperti kantin atau warung-warung makan belum paham pentingnya menghasilkan makanan yang halal sehingga para pelaku usaha tersebut belum memiliki sertifikat halal. Sertifikat halal bagi industri makanan dan minuman menjadi hal penting karena sertifikat halal memberikan kepastian kehalalan bagi suatu produk yang akhirnya akan memberikan ketenangan batin bagi masyarakat yang mengkonsumsinya Lembaga Pengkajian Obat dan Makanan, (2012).

Pengajuan sertifikat halal untuk suatu produk didaftarkan ke LPPOM MUI baik di tingkat pusat atau provinsi. Sistem pengajuan sertifikat halal dapat dilakukan secara online melalui Cerol (certifikat online) Lembaga Pengkajian Obat dan Makanan, (2012). LPPOM MUI dengan sistem cerol, memberikan kemudahan bagi pelaku usaha untuk mendaftar sertifikat halal. Akan tetapi bagi beberapa industri terutama UMKM sistem cerol ini dinilai menyulitkan sehingga pelaku usaha malas untuk mendaftarkan sertifikat halal bagi produknya.

Dari uraian di atas maka dirasakan perlunya memberikan Workshop dan Pelatihan Pengajuan Sertifikat Halal Bagi Pelaku Industri Makanan Olahan UMKM di Wilayah Duren Sawit Jakarta Timur agar para pelaku usaha memiliki pemahaman pentingnya sertifikat halal dan memberikan kemudahan dalam mengajukan sertifikat halal secara online Hutomo, (2019).

\section{METODE PELAKSANAAN}

Berdasarkan analisis situasi lingkungan di wilayah mitra serta adanya permasalahan yang timbul yaitu minimnya kesadaran pelaku usaha di bidang makanan untuk mendaftarkan sertifikat halal, maka upaya untuk menyelesaikan permasalahan yang dihadapi oleh mitra dan mendukung program kerja dari PKHU adalah mengadakan Workshop dan Pelatihan Pengajuan Sertifikat Halal Bagi Pelaku Industri Makanan Olahan UMKM di Wilayah Duren Sawit Jakarta Timur Osakwe, Nomusa, \& Jere, (2017).

Pelaksana kegiatan ini adalah staf pengajar Fakultas Farmasi dan Sains UHAMKA Jakarta yang juga sebagai narasumber internal. Metode pelaksanaan yang dilakukan adalah dengan memberikan materi yang meliputi batasan halal dan haram menurut Al Qur'an dan Al hadist, pentingnya sertifikat halal bagi pelaku usaha. Pelatihan pendaftaran sertifikat secara halal secara online yang dilakukan secara berkelompok didampingi satu fasilitator 
untuk tiap kelompok. Sebagai nara sumber eksternal akan diberikan oleh Dinas DPE Jakarta Timur dengan materi cara mendaftarkan sertifikat halal secara gratis.

Hasil workshop dan pelatihan ini diharapkan dapat meningkatkan kesadaran pelaku usaha akan pentingnya sertifikat halal yang pada akhirnya akan meningkatkan jumlah pelaku usaha yang mendaftar sertifkat halal.

Metode yang digunakan pada kegiatan ini adalah:

\section{Ceramah}

Tahapan ini peserta diberikan materi tentang batasan halal dan haram menurut $\mathrm{Al}$ Qur'an dan Al hadist, pentingnya sertifikat halal, langkah-langkah dalam pendaftaran sertifikat halal, cara mendaftarkan sertifikat halal secara gratis, melalui ceramah dan modul/materi.

2. Diskusi (Dialog interaktif, bimbingan teknis dan tanya jawab)

Tahapan ini berupa dialog/tanya jawab dan diskusi mengenai materi yang diberikan Roliana, (2018).

3. Pelatihan dengan demo yang dilakukan secara berkelompok.

Pelatihan secara langsung mengenai tahapan pendaftaran sertifikat halal secara online. Peserta akan dibagi-bagi dalam kelompok sesuai produk yang dihasilkan. Setiap kelompok akan didampingi oleh satu fasilitator.

4. Evaluasi

Evaluasi dilakukan dalam 2 tahap,

a. Tahap pertama adalah bentuk test (pre-test dan post-test) untuk mengetahui kemampuan peserta akan materi yang diberikan.

b. Tahap kedua adalah memantau para pelaku usaha dalam mendaftarkan sertifikasi halal untuk produknya. Pada tahap ini PKHU menjadi pendamping pelaku usaha UMKM yang menjadi peserta workshop selama proses pengajuan sertifikasi halal Gudiené, Banaitis, Podvezko, \& Banaitienė, (2014).

\section{PEMBAHASAN}

Undang-undang No. 33 Tahun 2014 tentang Jaminan Produk Halal (JPH) telah berlaku efektif pada 17 Oktober 2019. UU JPH mengatur kewajiban untuk melakukan sertifikasi halal untuk para pelaku usaha. Pasal 4 menyebutkan: Produk yang masuk, beredar, dan diperdagangkan di wilayah Indonesia wajib bersertifikat halal. Adapun produk yang wajib disertifikasi halal adalah sebagaimana tercantum pada pasal 1 ayat 1 UU No. 33 Tahun 2014 dan pasal 1 ayat 2 PP No. 31 Tahun 2019: Produk adalah barang 
dan/atau jasa yang terkait dengan makanan, minuman, obat, kosmetik, produk kimiawi, produk biologi, produk rekayasa genetik, serta barang gunaan yang dipakai, digunakan, atau dimanfaatkan oleh masyarakat. Pelaksanaan sertifikasi halal per tanggal 17 Oktober 2019 dilakukan pemerintah melalui Badan Penyelenggara Jaminan Produk Halal (BPJPH) Lembaga Pengkajian Obat dan Makanan \& MUI, (2019).

Halal merupakan kebutuhan pasar yang sedang berkembang pesat. Populasi muslim di dunia 28,68\% dari populasi dunia atau 2,18 miliar sedangkan di Indonesia sendiri mencapai 207 juta atau 87,2\% dari jumlah penduduk di Indonesia Kementerian Komunikasi dan Informatika RI, (2019). Oleh sebab itulah penting bagi UMKM untuk mendapatkan sertifikat halal agar bisa bersaing dengan industry-industri yang lain.

Pelaku usaha yang ingin memperoleh sertifikat halal MUI, baik industry pengolahan (pangan, obat, kosmetika), rumah potong hewan (RPH), dan restoran/katering/dapur, harus melakukan pendaftaran sertifikasi halal dan memenuhi persyaratan sertifikasi halal. Tahapan-tahapan yang harus dilewati perusahaan yaitu: memahami persyaratan sertifikasi halal dan mengikuti pelatihan Sistem Jaminan Halal (SJH), menerapkan SJH, menyiapkan dokumen sertifikasi halal, melakukan pendaftaran sertifiaksi halal (menggunggah data ke Cerol), melakukan monitoring pre audit dan pembayaran akad sertifikasi, pelaksanaan audit, melakukan monitoring pasca audit, dan memperoleh sertifikat halal Lembaga Pengkajian Obat dan Makanan MUI, (2018) .

Evaluasi yang dilakukan untuk para peserta kegiatan ini adalah pre-test dan posttest. Hasil uji statistik (paired sample) menunjukkan bahwa terjadi peningkatan pemahaman tentang halal dan proses sertifkasi halal $(\mathrm{p}<0,05)$. Hasil evaluasi ditampilkan pada Gambar 1. Grafik evaluasi menggambarkan perbedaan nilai yang didapat sebelum dan sesudah dilakukan workshop dan pelatihan, tampak jelas peningkatan yang terjadi, bahkan salah seorang peserta mendapatkan nilai 100 yang artinya dapat menjawab semua pertanyaan dengan benar Cho, Lee, Joo, \& Becker, (2018). 


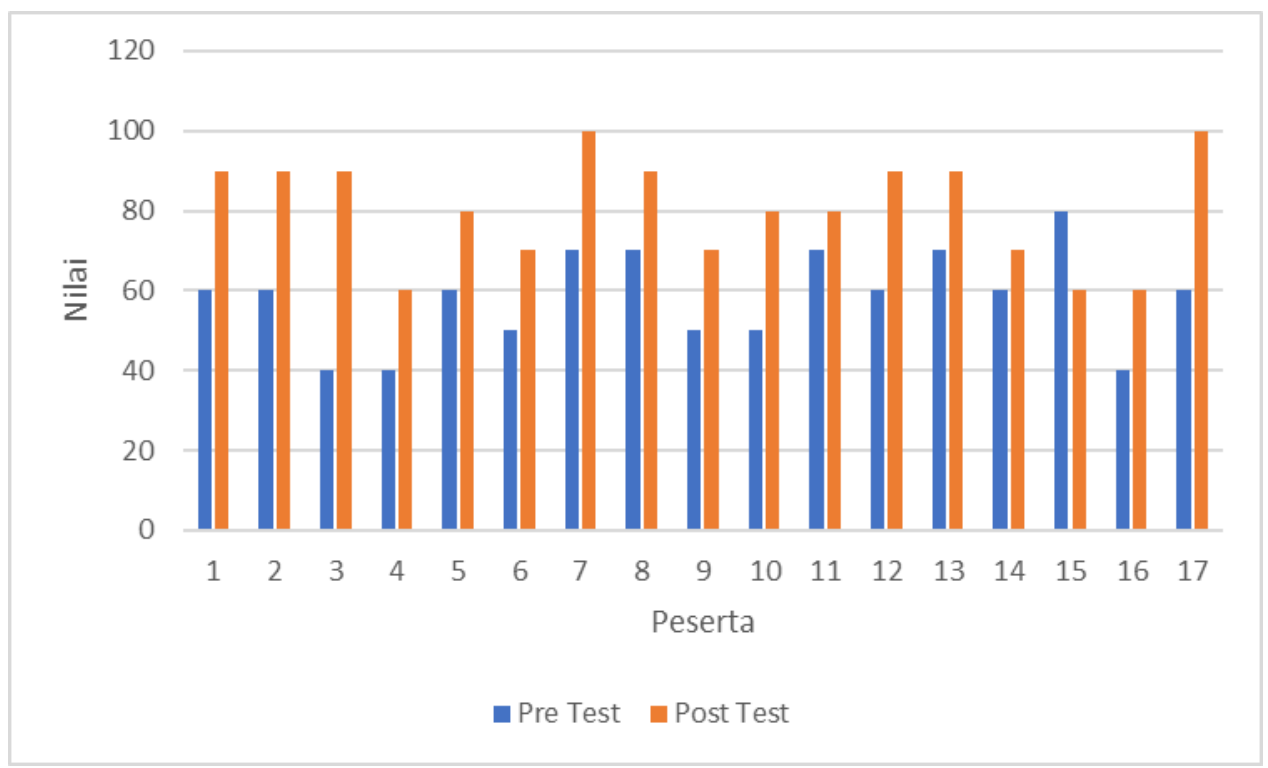

Gambar 1. Hasil Evaluasi Peserta Workshop Pengajuan Sertifikasi Halal

Transfer ilmu dari kegiatan ini dilakukan oleh tim dosen dari PKHU FFS UHAMKA sebagai pemateri adalah Dr. Siska, M.Farm., Apt. dan Ema Dewanti, M.Si dengan moderator Hanifah Rahmi, M.Biomed. Kegiatan edukasi tentang halal diharapkan dapat berkelanjutan untuk mendorong Gerakan Masyarakat Sadar Halal (Gemar Halal).

Alhamdulillah kegiatan ini dapat berjalan dengan baik tanpa kesulitan yang berarti. Target luaran diharapkan peserta pelatihan melakukan pendaftaran sertifikasi halal untuk produk yang mereka hasilkan. Tindak lanjut dari kegiatan ini adalah memberikan konsultasi halal untuk mempersiapkan proses sertifikasi. Kegiatan ini didukung sepenuhnya oleh Pimpinan Universitas UHAMKA di bawah koordinasi Wakil Rektor IV dengan mencanangkan Sertifkasi Halal untuk kantin di lingkungan kampus UHAMKA.

Foto-foto kegiatan dapat dilihat pada Gambar 2, 3, dan 4.

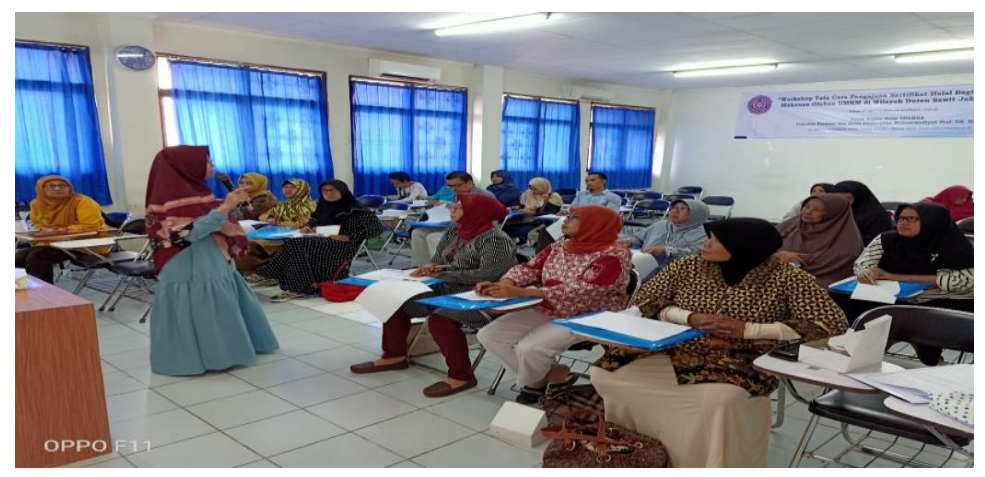

Gambar 2. Pemaparan Materi tentang Persyaratan dan Tatacara Sertifikasi Halal 


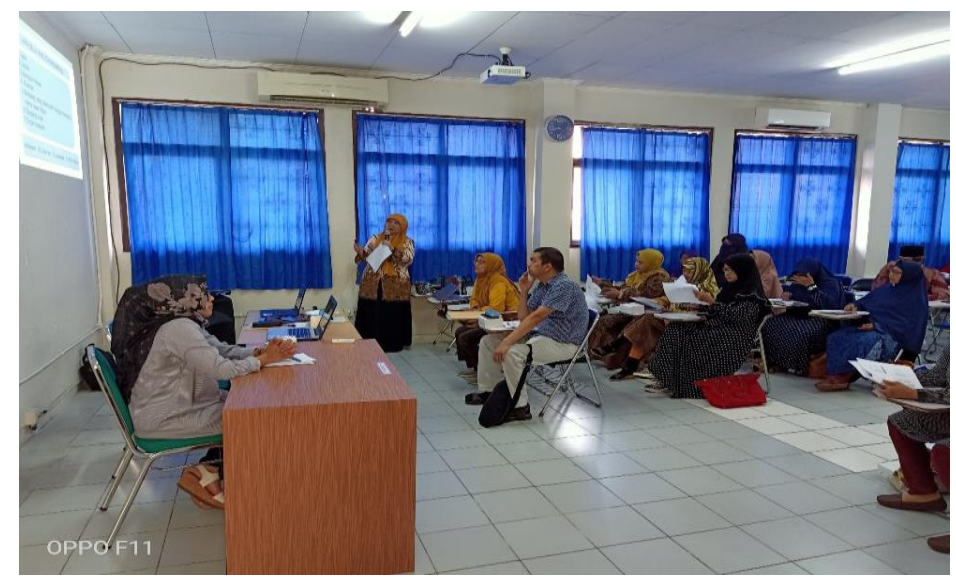

Gambar 3. Pemaparan Materi tentang Pentingnya Halal

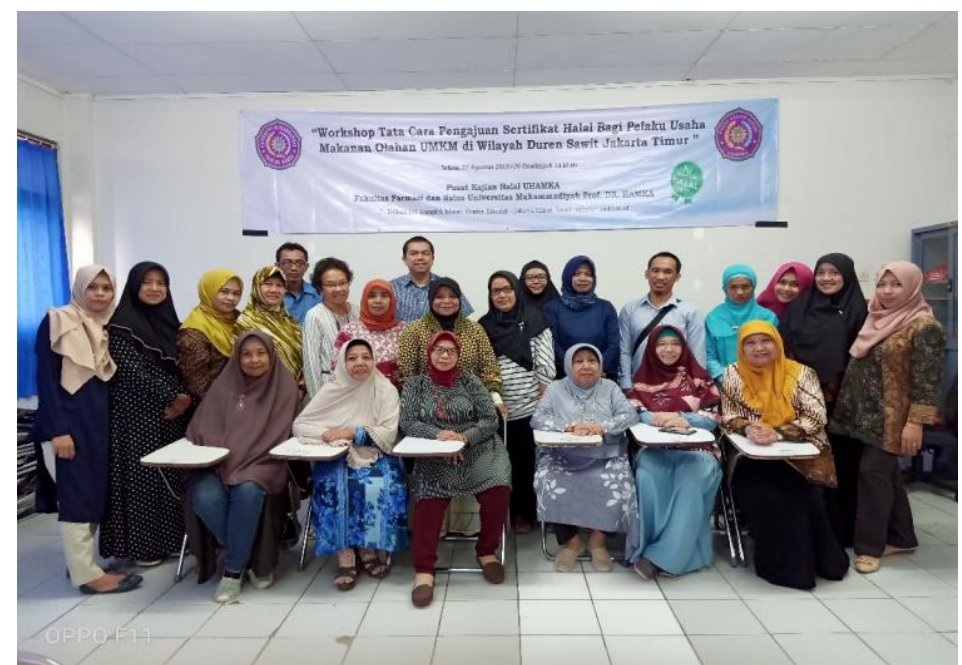

Gambar 4. Foto bersama dengan para peserta Workshop

\section{KESIMPULAN}

Pelatihan pengajukan sertifikasi halal memberikan dampak positif bagi para peserta. Hal ini terbukti dari hasil evaluasi yang dilakukan. Metode yang diterapkan dalam kegiatan ini sesuai dengan masalah yang dihadapi para pelaku usaha UMKM khususnya di wilayah Duren Sawit. Dampak kegiatan ini adalah dicanangkannya sertifikasi halal untuk kantin di lingkungan UHAMKA sebagai role model adalah kantin di Fakultas Farmasi dan Sains. Pelatihan dan edukasi ini diharapkan dapat berlangsung secara berkelanjutan dan dapat menjangkau pelaku UMKM di wilayah yang lain.

\section{UCAPAN TERIMA KASIH}

Terima kasih kami sampaikan kepada Lembaga Pengabdian Pada Masyarakat (LPPM) Univeristas Muhammadiyah Prof. Dr. HAMKA yang telah mendukung secara materi pada kegiatan ini melalui Surat Perjanjian Kontrak No. 80/H.04.02/2019. Terima kasih kami sampaikan kepada Pusat Kajian Halal UHAMKA (PKHU) yang telah 
memfasilitas, serta kepada Dekan dan para Wadek FFS UHAMKA yang telah mengizinkan penggunaan sarana dan prasarana untuk penyelenggaraan kegiatan ini.

\section{DAFTAR PUSTAKA}

Cho, K., Lee, S., Joo, M.-H., \& Becker, B. (2018). The Effects of Using Mobile Devices on Student Achievement in Language Learning: A Meta-Analysis. Education Sciences, 8(3), 105. https://doi.org/10.3390/educsci8030105

Gudienė, N., Banaitis, A., Podvezko, V., \& Banaitienè, N. (2014). Identification and evaluation of the critical success factors for construction projects in Lithuania: AHP approach. Journal of Civil Engineering and Management, 20(3), 350-359.

Hutomo, A. (2019). Pengaruh Pelatihan Teknik Announcing Terhadap Peningkatan Kualitas Pemandu Acara (MC) Bagi Remaja Kampung Cerdas. Jurnal Komunikasi, 10(1), 83-88.

Kementerian Agama, \& RI. (n.d.). Al Qur`an.

Kementerian Komunikasi dan Informatika RI. (2019). Portal Informasi Indonesia.

Lembaga Pengkajian Obat dan Makanan, M. U. I. (2012). Persyaratan Sertifikasi Halal HAS 23000. Bogor: LPPOM MUI.

Lembaga Pengkajian Obat dan Makanan MUI. (2018). Prosedur Sertifikasi Halal MUI.

Lembaga Pengkajian Obat dan Makanan, \& MUI. (2019). Penjelasan LPPOM MUI terkait Sertifkasi Halal.

Osakwe, J. O., Nomusa, D., \& Jere, N. (2017). Teacher and Learner Perceptions on Mobile Learning Technology: A Case of Namibian High Schools from the Hardap Region. HIGHER EDUCATOR-An International Journal, 1(1), 13-41. https://doi.org/10.26762/he.2017.30000002

Presiden Republik Indonesia. Undang-Undang Jaminan Produk Halal, Pub. L. No. No. 33 (2014).

Roliana, E. (2018). Urgensi Pengenalan Konsep Bilangan Pada Anak Usia Dini. In Prosiding Seminar dan Diskusi Nasional Pendidikan Dasar 2018 (pp. 417-420).

Setyaningsih, D, Apriyantono, A, dan Sari, M. (2010). Analisa Sensori Industri Pangan dan Agro. bogor: IPB Press. 